\section{G157(P) A TOOLKIT TO IDENTIFY BARRIERS TO DISCHARGE FOR CHILDREN WITH MEDICAL COMPLEXITY}

${ }^{1} \mathrm{M}$ Salama, ${ }^{1}$ RK Shanahan, ${ }^{2}$ EZA Bassett, ${ }^{1} \mathrm{MR}$ Kelly, ${ }^{1} \mathrm{KJ}$ Ellicott, ${ }^{1} \mathrm{G}$ Campbell. ${ }^{1}$ Children with Medical Complexities Team, Birmingham Children's Hospital, Birmingham, UK; ${ }^{2}$ Dept of Paediatrics, Royal United Hospitals Bath NHS FT, Bath, UK

\subsection{6/archdischild-2020-rcpch.128}

Background The Children with Medical Complexities (CMiC) team is a multidisciplinary team working in a tertiary children's hospital. Our aim is to provide a pop up service for children with medical complexity (CMC) tailored to the individual child and family. We describe the co-production, development and implementation of our CANVAS toolkit which captures information about the barriers to discharge to enable us to work to a smoother and earlier discharge.

Aim To develop a mechanism to categorize barriers to discharge faced by CMC to enable working towards a faster and better discharge.

Method Since 2013 we have been part of a weekly meeting where we discuss barriers to discharge for patients with lengths of stay (LOS) over 30 days. This identified a number of areas including housing, care provision and training. In 2014 we started collaborating with colleagues from social care, occupational therapy and community nursing to develop a forum for continued conversation around this group of children. With these stakeholders, parents with lived experience and young people from the Young Persons Advisory Group, we ran a process mapping exercise exploring the themes around barriers to getting home for CMC. We used all these avenues of information to develop the CANVAS categories and expanded toolkit.

Results CANVAS categories were identified as follows. We have also developed specific data points in each category. 1. Care and commissioning 2. Allied health professionals and equipment 3. Medical Needs 4. adVocacy and educations 5. Accomodation 6. Safeguarding.

Discussion The $\mathrm{CMiC}$ team has been working to improve how we support this group of children since its creation in 2014. The categories above enable us to capture all the challenges that we have faced as a team in supporting discharge for CMC. Together they enable us to provide an easily captured and communicated view of the palette of colour-coded care each child and family needs at any given point in time. We hope that prolonged data capture may enable early recognition of potential blockers for the individual as well as larger scale system issues.

\section{G158(P) HUMAN FACTORS FACULTY DEVELOPMENT IN A TERTIARY CHILDREN'S HOSPITAL}

${ }^{1} \mathrm{M}$ Salama, ${ }^{2} \mathrm{~A}$ Walker. ${ }^{1}$ Department of General Paediatrics, Birmingham Children's Hospital, Birmingham, UK; ${ }^{2}$ Department of Anaesthetics, Birmingham Children's Hospital, Birmingham, UK

\subsection{6/archdischild-2020-rcpch.129}

Aim Human factors and ergonomics (HFE) is the discipline examining the way humans interact with systems. It is a key consideration when understanding safety. Within the healthcare sector there is a growing recognition of its importance. Crosspollination of learning especially from the aviation industry has led to increased awareness and integration into health settings. This has been facilitated by the Clinical Human Factors
Group $^{1}$ in addition to more recent guidance from the Chartered Institute of Ergonomics and Human Factors. ${ }^{2}$

Methods Within our tertiary children's hospital recognition of its importance led to training of senior leadership teams. In 2015 we obtained funding to expand this training. 55 senior medical and nursing staff were trained in a 2-day master-class by Terema. 11 went on to attend a 3-day Training the Trainer Course. Through mentorship faculty began delivering a bespoke HFE single day training course. We have delivered approximately 26 courses over this 4 -year period to over 400 staff. Each course has comprised of varied personnel from administrative and laboratory staff to frontline health care workers and managers.

Results Qualitative feedback following the courses has been overwhelmingly positive. This reflects the overarching aim of maintaining psychological safety. Attendees appreciated a different perspective on why things go wrong. In addition to direct teaching, many levels within our organisation across professional and physical boundaries have been influenced by ergonomic principles. Aspects of the training are being taught to all newly qualified nurses, trainee doctors and new consultants as well as new theatre staff. Additionally, we have taught at simulation courses, departmental audit and ward away days. Understanding the systems aspect of ergonomics has led to quality improvement (QI) initiatives such as briefing and debriefing boards, the hydration bundle, the extravasation project, and a recent ergonomic redesign of our early warning score.

Conclusion The spread of ergonomic awareness into different areas has been organic and unplanned. The natural alignment with QI is well recognised. ${ }^{3}$ The challenge ahead is to provide data rich evidence of its impact.

\section{REFERENCES}

1. CHFG website.

2. CIEHF white paper.

3. https://qualitysafety.bmj.com/content/24/4/250

\section{G159(P) NEO-TRAIN QUALITY IMPROVEMENT INITIATIVE TO IMPROVE EOSIN (EARLY ONSET SEPSIS IN NEONATES) CARE AS PER NICE RECOMMENDATION}

A Oommen, N Singh, K Yadav, D Saxena, M Ainsworth, A Pamina, J Paul. Neonatology, University Hospitals of Leicester, Leicester, UK

\subsection{6/archdischild-2020-rcpch.130}

Background Sepsis in neonates is a common occurrence and can be difficult to detect in the early stages.

NICE (National Institute of Clinical Excellence) had produced guidelines on neonatal sepsis (NICE CG149, 2012). The aim of the project was to ensure adherence to the guidelines and improve quality of care.

Aim 100\% compliance with NICE Sepsis standards (antibiotics administration within 1 hour of suspecting sepsis being the primary objective)

Prescription sheets and patient notes review and if $100 \%$ compliance with NICE guidance CG 149 (2012) was achieved.

An environmental restructuring, education and training of staff and persuasion of stakeholders.

Methodology PDSA cycles: Four PDSA (Plan-Do-Study-Act) cycles with formative rapid approach were run in two six monthly blocks with between the $02 / 2017$ to $07 / 2017$ and $08 /$ 2018 to $01 / 2019$. 